\title{
Milan system in salivary gland lesions: Its diagnostic and clinical relevance
}

\author{
Smriti Singh'1, Praveen Rana², Swaran Kaur ${ }^{3}$, Uma Garg ${ }^{4}$, Deepti Agrawal', \\ Abhishek Saini ${ }^{6}$ \\ ${ }^{1,6}$ Post Graduate Resident, ${ }^{2,5}$ Professor, ${ }^{3}$ Professor and Head, Department of Pathology, ${ }^{4}$ Professor and Head, \\ Department of ENT, BPS GMC for Women, Khanpur Kalan, Haryana, India
}

Background: The salivary gland lesions constitute around 3-6\% of all head-and-neck lesions and have always posed a diagnostic riddle for the cytopathologists around the world. Since the majority of these lesions need surgical excision, it is, therefore, important to diagnose these lesions with utmost precision to prevent over or under stage procedures. The recent adaption of Milan system of reporting aims to establish a uniform, accurate, and consensual reporting system which bridges the communication between the pathologists and the clinicians. Aims and Objectives: The current study aims to assess the diagnostic application of Milan system and aims to reclassify the lesions according to it. Materials and Methods: The current study was conducted at our institute during 1 year period. All salivary gland swellings presenting to the fine-needle aspiration cytology (FNAC) section during this period were included in the study. Along with this, records and slides of cases of salivary gland lesions were retrospectively assessed. All relevant data and radiologic findings were retrieved from the case records. FNAC was done using $23 \mathrm{G}$ needle. The slides were stained with both Leishman and Papanicolaou stain wherever possible. Quantitative data were expressed as mean and standard deviation and percentages. All the 83 lesions were reclassified as per the Milan system. Histopathology was available in 42 cases. Inclusion criteria: All the samples of the patient having salivary gland lesion(s) whose FNAC were performed in the department of pathology. Statistical Analysis: Data were be entered into Microsoft Excel spreadsheets. For quantitative data, mean and standard deviation were calculated. For qualitative data, percentage and proportion were calculated. Sensitivity, specificity, and spearman correlation between FNAC and histopathology were calculated. $\mathrm{P}<0.05$ was considered statistically significant. Results: The total of 83 cases was included in our study. The cytological analysis was done and all cases were classified as per Milan system. The age of patients ranged from 4 years to 77 years with a mean age of 43 years. Parotid was the most frequently involved gland in which a total of 51 cases $(61.4 \%)$ were reported. The most common benign tumor reported on cytology was pleomorphic adenoma and the most common malignant tumor reported was adenoid cystic carcinoma. On recategorization of lesions as per Milan system, the category IVA, that is, benign salivary gland neoplasm had the maximum number of lesions (40) accounting for $48.1 \%$ of all the lesions. Histopathology was available in 42 cases. The predominant lesion on histopathology was pleomorphic adenoma (22). On statistical analysis of the data, the sensitivity was $71.4 \%$, specificity was $96.1 \%$, diagnostic accuracy as $62.1 \%$, and positive and negative predictive value as 83.3 and $92.5 \%$, respectively. Conclusion: Risk stratification approach in classifying salivary gland cytology aspirate as per Milan system provides a standardized reporting and better communication to clinician.

Key words: Fine-needle aspiration cytology; Milan system; Salivary gland
Access this article online

Website:

http://nepjol.info/index.php/AJMS DOI: 10.3126/ajms.v12i11.35103 E-ISSN: 2091-0576

P-ISSN: 2467-9100

Copyright (c) 2021 Asian Journal of Medical Sciences

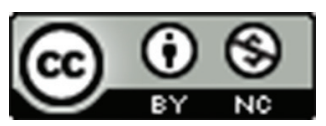

This work is licensed under a Creative Commons Attribution-NonCommercial 4.0 International License. 


\section{INTRODUCTION}

The salivary gland lesions have always posed a diagnostic challenge to the cytopathologists and clinicians alike. A small cystic lesion over a short duration on the buccal mucosa presenting with pain can be as benign as an infected salivary gland swelling or as malignant as the cystic component of the malignant neoplasm. The tumors are rare and account for around $6.5 \%$ of all head-and-neck tumors. ${ }^{1}$ The varied presentation, location, and erratic progression of these lesions warrant an urgent intervention. Radiological investigations have been successful to diagnose the lesions to a major extent but it is the fine-needle aspiration cytology (FNAC) which enables the clinicians to plan the patient management. The FNAC has been very instrumental in delineating the benign and malignant neoplasms and providing a definitive diagnosis to the clinicians. The ease of performing the FNAC, patient compliance, cost-effectiveness, and early results have all coupled to make it the first choice of investigation for clinicians. Nevertheless, the role of FNAC in pre-operative evaluation is not universally established and thus FNAC as a pre-operative tool has its own limitations. The use of smallsized needle may not sample the smears representative of the entire lesion. Majority of the cells arise from the same cell lines and often undergo metaplastic change which causes diagnostic problems in FNAC. ${ }^{2}$

Some salivary gland malignancies can only be distinguished from their benign counterpart by the presence of capsular invasion which is not assessable by FNAC. ${ }^{3}$

A need was felt for a consensual common reporting system which could serve as a common guiding system for pathologists around the globe. This is how the Milan system originated in September 2015 at the European Congress of Cytology, which was held in Milan, Italy. An international panel of 49 cytopathologists and histopathologists (the Milan group) was organized to establish a unified effort under the title of "The Milan System for Reporting Salivary Gland Cytopathology." Milan system was the result of this combined untiring effort of this group. This classification scheme is comprised seven diagnostic categories, including non-diagnostic (ND) (category 1), benign non-neoplastic (NN) (category 2), atypia of undetermined significance (AUS) (category 3), neoplasm benign (NB) (category 4a), salivary gland neoplasm of uncertain malignant potential (SUMP) (category 4b), suspicious for malignancy (SM) (category 5), and malignant (M) (category 6). ${ }^{4}$ This system aims to bring a standardized reporting system for the salivary gland lesions and bridge the gap between the cytopathologists and clinicians.

The present study was conducted to assess the diagnostic utility of FNAC in salivary gland lesions, to reclassify them as per the recently devised Milan system and assess the applicability and practicality of the Milan system.

\section{Aim}

To detect the diagnostic utility of fine needle aspiration cytology in salivary gland lesions using Milan System.

\section{Objective}

1. To assess the result of fine needle aspiration cytology in diagnosis of various salivary gland lesions and to classify them according to Milan system.

2. To correlate the results of fine needle aspiration cytology in salivary gland lesions with histopathology wherever possible and using ancillary techniques.

3. To study sensitivity, specificity and diagnostic accuracy of fine needle aspiration cytology in salivary gland lesions.

\section{MATERIALS AND METHODS}

The study was conducted on 83 salivary gland lesions at our institute over a period of 2 years. Records and slides of cases of salivary gland lesions were retrospectively assessed.

All relevant data and radiologic findings were retrieved from the case records. FNAC was done using $23 \mathrm{G}$ needle. In cases where the first attempt at aspiration was unsuccessful, a maximum of three passes were performed. In the case of large swellings, aspiration was done from at least two sites to minimize sampling error.

In case of cystic lesion, after complete evacuation, FNAC was done on any residual solid area. The fluid so aspirated was subjected to centrifugation and sediment smears were prepared. The slides were stained with both Leishman and Papanicolaou stain wherever possible. Quantitative data were expressed as mean and standard deviation and percentages. All the 83 lesions were reclassified as per the Milan system. Histopathological specimens were received in $10 \%$ buffered formalin and were grossed and processed according to standard protocols. Hematoxylin and eosin ( $\mathrm{H}$ and $\mathrm{E})$ staining was done as stated in standard literature. ${ }^{5}$

\section{Statistical analysis}

Data were be entered into Microsoft Excel spreadsheets. For quantitative data, mean and standard deviation were calculated. For qualitative data, percentage and proportion were calculated. Sensitivity, specificity, and spearman correlation between FNAC and histopathology were calculated. $\mathrm{P}<0.05$ was considered statistically significant.

\section{Ethics}

The procedures followed were in accordance with the ethical standards of the responsible committee on human 


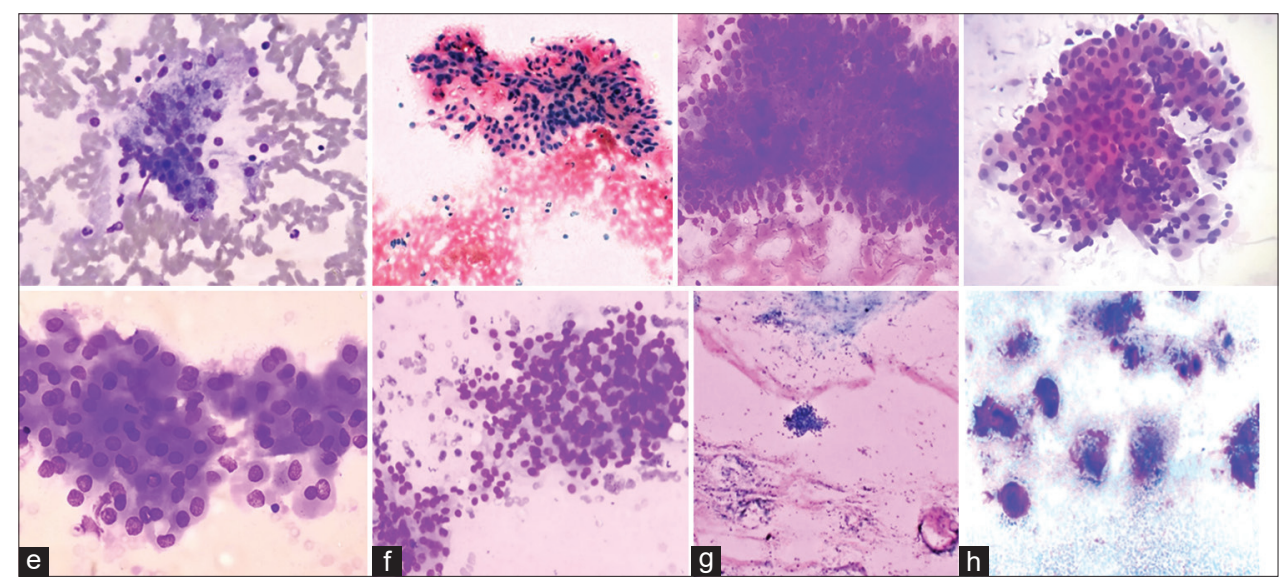

Figure 1: Microphotograph of cytology of various salivary gland lesions: (a) Chronic sialadenitis showing acinar cells along with inflammatory cells seen in the background (Leishman stain, $\times 400$ ). (b) Pleomorphic adenoma showing cells along with chondromyxoid stroma (Pap stain, $\times 400$ ). (c) Warthin tumor showing cohesive sheet of oncocytic cells along with lymphocytes and mast cells (Leishman stain, $\times 400$ ). (d) Warthin tumor showing cohesive sheet of oncocytic cells with abundant cytoplasm (Pap stain, $\times 400$ ). (e) Oncocytoma showing cohesive multilayered aggregates of oncocytic cells with bland nuclei (Leishman stain, $\times 400$ ). (f) Acinic cell carcinoma showing cellular smears composed of cells with vacuolated cytoplasm relatively bland nuclei and many naked nuclei (Leishman stain, $\times 400$ ). (g) Mucoepidermoid carcinoma (Pap stain $\times 100 \mathrm{X})$. (h) Adenoid cystic carcinoma showing smears with hyaline globules along with adherent tumor cells (Leishman stain, $\times 100)$

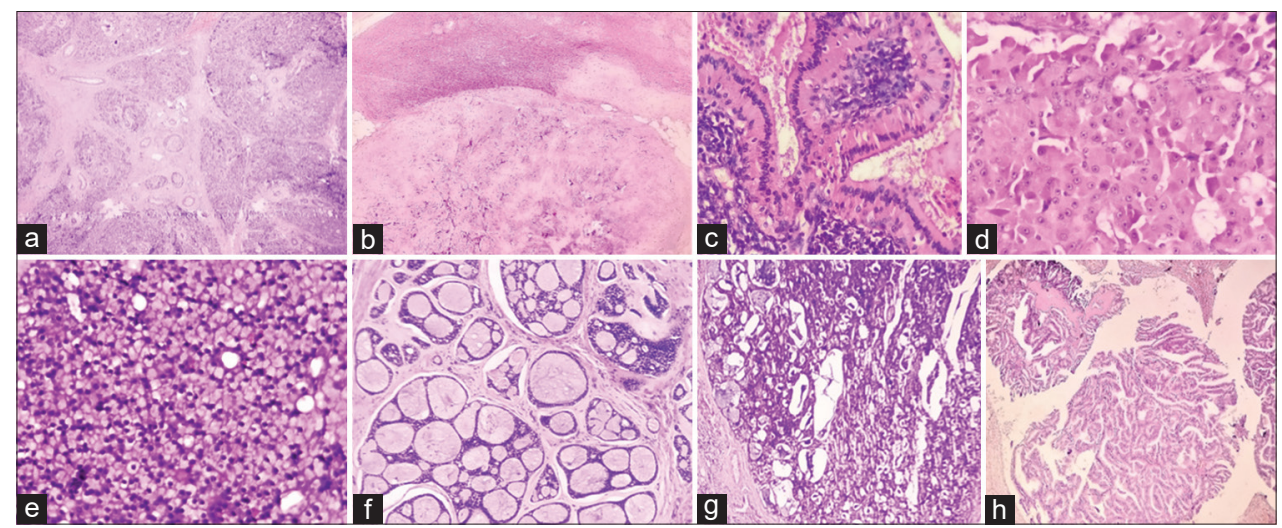

Figure 2: (a) Chronic sialadenitis showing fibrous tissue with inflammatory infiltrate and prominent ducts ( $\mathrm{H}$ and $\mathrm{E} \times 40)$. (b) Pleomorphic adenoma showing cellular and stromal component $(\mathrm{H}$ and $\mathrm{E}, \times 40)$. (c) Warthin tumor showing a double-layered epithelium resting on lymphoid stroma ( $H$ and $E, \times 400)$. (d) Oncocytoma showing tumor cells with bland oncocytic cytoplasm and nucleus with prominent nucleoli $(H$ and $E, \times 400)$. (e) Acinic cell carcinoma showing tumor cells with abundant granular cytoplasm ( $\mathrm{H}$ and $\mathrm{E}, \times 400)$. (f) Adenoid cystic carcinoma showing the cribriform pattern of growth $(\mathrm{H}$ and $\mathrm{E}, \times 400)$. (g) Mucoepidermoid carcinoma showing the mucous, squamous. and intermediate cells $(\mathrm{H}$ and $\mathrm{E}, \times 40)$. (h) Papillary cystadenocarcinoma showing papillary projections with nuclear pleomorphism $(\mathrm{H}$ and $\mathrm{E}, \times 40)$

experimentation (institutional or regional) and with the Helsinki Declaration of 1975, as revised in 1983.

\section{RESULTS}

A total of 83 cases were included in our study. The cytological analysis was done and all cases were classified as per Milan system. The age of patients ranged from 4 years to 77 years with a mean age of 43 years.

The maximum number of cases were seen in the age group of $41-50$ years comprising $24 \%$ of the total lesions (Table 1 ).

Females showed slightly greater predilection for salivary gland lesions than males which were 43 in number against 40 cases in males.
The majority of cases of cases are in the age group of $41-50$ years of age constituting $24 \%$ of lesions followed by $22.9 \%$ in the fifth decade. The least number of cases are in the age $<10$ years of age constituting only $2.4 \%$ of lesions.

The cytological analysis (Table 2) of majority of cases was reported as benign (43) followed by inflammatory (25), eight cases each of malignancy and inadequacy, and five cases of suspicious of malignancy. Majority of the benign cases (12) were reported in the age group of 51-60 years of age. The maximum number of malignant cases, four in each decade, were reported in the age of 41-60 years. The cytological diagnosis of our study (as shown in Figure 1) showed the most common lesion as pleomorphic adenoma (21) followed by a diagnosis of salivary gland neoplasm and chronic sialadenitis (16 
each). This was followed by diagnosis of cystic lesion (6) and three cases each of warthin tumor, salivary gland neoplasm with atypia, and adenoid cystic carcinoma. Cytological diagnosis of inadequate, salivary gland neoplasm with cystic change, granulomatous parotitis, and mucoepidermoid carcinoma was also listed in two cases each. We also reported one case each of parotid abscess, suggestive of neoplastic process, poorly differentiated neoplasm, suspicious of malignancy, positive for malignancy, poorly differentiated malignancy, and acinic cell carcinoma. Parotid was the most frequently involved gland in which a total of 51 cases $(61.4 \%)$ were seen followed by submandibular (31) and one lesion in soft palate. The most common benign tumor reported on cytology was pleomorphic adenoma and most common malignant tumor reported was adenoid cystic carcinoma.

On recategorization of lesions as per Milan system (Table 3), the category IVA, that is, benign salivary gland neoplasm had the maximum number of lesions (40) accounting for $48.1 \%$ of all the lesions. This was followed by NN category with 19 lesions followed by category of $\mathrm{NB}$ of uncertain malignant potential, suspicious of malignancy and malignant category (four each). This was

\begin{tabular}{lcc}
\multicolumn{3}{l}{ Table 1: Age-wise distribution of cases } \\
\hline Age group (in years) & Number of cases & Percentage \\
\hline $0-10$ & 2 & 2.4 \\
$11-20$ & 8 & 9.6 \\
$21-30$ & 13 & 15.7 \\
$31-40$ & 11 & 13.3 \\
$41-50$ & 20 & 24.1 \\
$51-60$ & 19 & 22.9 \\
$61-70$ & 5 & 6.0 \\
$71-80$ & 5 & 6.0 \\
Total & 83 & 100 \\
\hline
\end{tabular}

followed by ND category and atypia of undetermined category with three cases in each category.

On cytological analysis of 83 cases, most of the lesions were categorized as benign. Majority of benign lesions were pleomorphic adenoma (21) followed by salivary gland neoplasm (16). The second major category was of inflammatory lesions (25). Chronic sialadenitis was the major lesion in this category (16) followed by cystic lesions (6). The malignant category included eight cases with three cases of adenoid cystic carcinoma, two of mucoepidermoid carcinoma and one of acinic cell carcinoma. Five cases were suspicious of malignancy with three reported as salivary gland neoplasm with atypia and one each of poorly differentiated neoplasm and suspicious of malignancy. Two lesions were reported as inadequate for cytological analysis.

Leishman and Papanicolaou stained smears of all cases were reevaluated and reclassified as per the Milan system. Clearly, NB was the most common category followed by the NN category.

In the current study, the histopathological diagnosis are shown in Figure 2 was available in 42 cases. Out of the available correlational Cases, the cytological diagnosis and its corresponding histopathological diagnosis are listed as below.

The cytological and histopathological correlation of various lesions is shown above. The maximum correlation was seen in pleomorphic adenoma.

Comparative analysis of various studies

\begin{tabular}{|c|c|c|c|c|}
\hline Cytological category & Cytological diagnosis & Number of cases & Total number of cases & Percentage \\
\hline Inadequate & Inadequate & 2 & 2 & 2.40 \\
\hline \multirow[t]{4}{*}{ Inflammatory } & Cystic lesion & 6 & 25 & 7.33 \\
\hline & Parotid abscess & 1 & & 1.20 \\
\hline & Chronic sialadenitis & 16 & & 19.27 \\
\hline & Granulomatous parotitis & 2 & & 2.40 \\
\hline \multirow[t]{5}{*}{ Benign } & Suggestive of neoplastic process & 1 & 43 & 1.20 \\
\hline & Pleomorphic adenoma & 21 & & 25.30 \\
\hline & Warthin's tumor & 3 & & 3.61 \\
\hline & Salivary gland neoplasm & 16 & & 19.27 \\
\hline & Salivary gland neoplasm with cystic change & 2 & & 2.40 \\
\hline \multirow[t]{3}{*}{ Suspicious of malignancy } & Salivary gland neoplasm with atypia & 3 & 5 & 3.61 \\
\hline & Poorly differentiated neoplasm & 1 & & 1.20 \\
\hline & Suspicious of malignancy & 1 & & 1.20 \\
\hline \multirow[t]{6}{*}{ Malignant } & Positive for malignancy & 1 & 8 & 1.20 \\
\hline & Mucoepidermoid carcinoma & 2 & & 2.40 \\
\hline & Acinic cell carcinoma & 1 & & 1.20 \\
\hline & Adenoid cystic carcinoma & 3 & & 3.61 \\
\hline & Poorly differentiated malignancy & 1 & & 1.20 \\
\hline & Total & 83 & 83 & 100 \\
\hline
\end{tabular}




\section{DISCUSSION}

In the present study, the most common age of presentation for lesions was seen in the age group 40-50 years of age which constituted around $24 \%$ of the lesions. In our study, the youngest case was of 4 years of age and oldest was of 77 years of age.

This finding was in concordance with the study conducted by Kumar et al., ${ }^{6}$ Goel et al., ${ }^{7}$ and Sharma et al. ${ }^{8}$

Panchal et al., ${ }^{9}$ have reported the most common age of presentation for the lesions during the third decade of life.

This constituted around $30 \%$ of all the reported lesions in their study. The current study has shown a predominance of the lesions in females. The male-to-female ratio for the prevalence of salivary lesions in our study is almost 1:1.02. Out of the total lesions reported in females, $84 \%$ of the lesions were benign and 14\% were malignant. Whereas in males, around $82.5 \%$ of lesions were benign and $15 \%$ were in the malignant category. Around $2 \%$ lesions were

\begin{tabular}{|c|c|c|c|}
\hline $\begin{array}{l}\text { S. } \\
\text { No. }\end{array}$ & Milan category & $\begin{array}{l}\text { Number } \\
\text { of lesions }\end{array}$ & Percentage \\
\hline 1. & Non-diagnostic & 06 & 7.3 \\
\hline 2. & Non-neoplastic & 19 & 22.9 \\
\hline 3. & $\begin{array}{l}\text { Atypia of undetermined } \\
\text { significance }\end{array}$ & 03 & 3.6 \\
\hline $4 \mathrm{~A}$. & Benign neoplasm & 40 & 48.2 \\
\hline 4B. & $\begin{array}{l}\text { Benign neoplasm of } \\
\text { uncertain malignant } \\
\text { potential }\end{array}$ & 05 & 6 \\
\hline 5. & Suspicious of malignancy & 05 & 6 \\
\hline \multirow[t]{2}{*}{6.} & Malignant & 05 & 6 \\
\hline & Total & 83 & 100 \\
\hline
\end{tabular}

inadequate on cytology in both the genders. Females preponderance in the salivary pathologies has also been reported by Ameli et al., ${ }^{10}$ and Panchal et al. ${ }^{9}$ However, a majority of the reported studies in the literature including as reported by Kumar et al., ${ }^{6}$ Sharma et al., ${ }^{8}$ and Rohilla et al. ${ }^{11}$

A particular notable feature in the current study is that we have reported two cases of warthin tumor in females. This is in contrary to the common notion that it is an exclusive entity to the male gender. In the available literature, only one study done by Kennedy ${ }^{12}$ has reported 35 cases of warthin tumor in females. The site of the lesion has its importance in the fact that a number of lesions have shown predominance for particular salivary glands as stated in established literature. ${ }^{13}$ Lesions as chronic sialadenitis have been reported in the submandibular glands. Furthermore, lesions such as warthin tumor have been reported majorly in the parotids as mentioned in the established literature. Thus, the site of lesion does offer a vital clue in diagnosing the lesions. The most common site of lesions as reported by our study is parotid glands constituting a total of 51 cases $(61.4 \%)$ of the lesions followed by submandibular glands and only one lesion has been reported in the soft palate. The results are similar to that reported by Ersoz et al., ${ }^{14}$ and Singh et al., ${ }^{15}$ and Koirala et al. ${ }^{2}$ The case was reported as salivary gland neoplasm, and on Milan recategorization, it was reclassified in the SM category.

Benign lesions were the most common category of lesions reported in the current study. The most common lesions reported in the study is pleomorphic adenoma which constituted a total of $25.3 \%$ of the lesions. About $19.27 \%$ of lesions were reported as salivary gland neoplasm and out of these $12 \%$ of the lesions were reported as salivary gland neoplasm most probably pleomorphic adenoma. They were followed by sialadenitis forming $19.27 \%$ of the

\begin{tabular}{lclr} 
Table 4: Analysis of cytological diagnosis of salivary & gland lesions with histopathology diagnosis \\
\hline Cytological diagnosis & Number of cases & Histopathological diagnosis & Number of cases \\
\hline Inadequate & 01 & Chronic sialadenitis & 01 \\
Cystic lesion & 03 & Pleomorphic adenoma & 01 \\
& & Warthin's tumor & 01 \\
Epidermal cyst & 02 & Mucoepidermoid carcinoma & 01 \\
Sialadenitis & 08 & Pleomorphic adenoma & 02 \\
Neoplastic process of salivary gland origin & 01 & Sialadenitis & 08 \\
Salivary gland neoplasm & 05 & Warthin's tumor & 01 \\
& & Pleomorphic adenoma & 02 \\
& & Adenoid cystic carcinoma & 01 \\
Pleomorphic adenoma & & Papillary cyst adenocarcinoma & 01 \\
Warthin's tumor & 16 & Oncocytoma & 01 \\
Salivary gland neoplasm with atypia & 01 & Pleomorphic adenoma & 16 \\
Possibility of mucoepidemoid carcinoma & 01 & Warthin's tumor & 01 \\
Acinic cell carcinoma & 02 & Pleomorphic adenoma & 01 \\
Adenoid cystic carcinoma & 01 & Mucoepidermoid carcinoma & 02 \\
Total & 01 & Acinic cell carcinoma & 01 \\
\hline
\end{tabular}




\section{Table 5: Comparison of statistical analysis}

\begin{tabular}{|c|c|c|c|c|}
\hline Reference study & Number of cases & Sensitivity & Specificity & Diagnostic accuracy (\%) \\
\hline Piccoioni et al., ${ }^{23}$ & 176 & 81 & 99 & 97 \\
\hline Stow et al., ${ }^{24}$ & 104 & 86.5 & 92.3 & 92.3 \\
\hline Lukas and Duskova ${ }^{25}$ & 107 & 89.2 & 85 & 97.2 \\
\hline Present study & 83 & 71.4 & 96.1 & 62.5 \\
\hline
\end{tabular}

total lesions reported on cytopathology. The results were similar to that reported by Kumar et al., ${ }^{16}$ and Devi. ${ }^{17}$ Out of the 83 cases, a diagnosis suggestive of malignancy was rendered in thirteen cases. The diagnostic terminology ranged from neoplasm with atypia to providing a definitive diagnosis of malignant neoplasm. About $15.6 \%$ of the lesions in the present study were diagnosed as malignant. Histopathological diagnosis was available in five out of 13 cases. Three cases were falsely diagnosed as nonmalignant lesions and hence false-negative cases. The various diagnostic terms that were used to provide the cytological malignancy diagnosis were given as stated. Three cases were reported as salivary gland neoplasm with atypia and one case each as poorly differentiated salivary gland neoplasm, suspicious of malignancy, positive for malignancy, and poorly differentiated malignancy. A definite diagnosis of malignancy was given in three cases of adenoid cystic carcinoma, two cases of mucoepidermoid carcinoma and one case of acinic cell carcinoma.

To bring uniformity in reporting, international experts in salivary gland cytopathology proposed the Milan system in 2015, a risk-based stratification system, similar to that of the Bethesda system for reporting cervical and thyroid cytology. ${ }^{18}$ Milan system of reporting is the new advancement in the field of salivary gland cytopathology. It is a new formulation that aids to diagnose the salivary gland lesions with better precision. It attempts to form a uniform diagnostic criteria for the lesions and thus reclassifies the various lesions into six categories. The inadequacy criteria have not been listed as definite cells but till date, the Bethesda criteria of minimum 60 lesional cells have been the most common trend followed in the literature. ${ }^{18,19} \mathrm{On}$ recategorization of the lesions as per the Milan system, the distribution of lesions was as follows - I. ND 7.2\%, II. NN $22.9 \%$, III. AUS 3.6\%, IVA. NB 49.4\%, IVB. SUMP $4.8 \%$, V. SM 6\%, and VI. M 6\%. The results were similar to as reported by Kala et al., ${ }^{20}$ where they have reported the Milan distribution as ND (6.1\%), NN (38.2\%), AUS $(2.7 \%), \mathrm{NB}(33.4 \%), \operatorname{SUMP}(2.0 \%), \mathrm{SM}(2.4 \%)$, and M $(15 \%)$ also reported the maximum cases under the category of benign as $31.4 \%$ of total lesions. The other categories reported lesions as ND 12\%, NN 28.5\%, AUS 6.5\%, SUMP $9.9 \%$, SM 2.7\%, and M 9.4\%. Katta and Chaganti ${ }^{21}$ have also reported maximum lesions in the benign category on recategorization as per the Milan System as 62.3\%. Other lesions constituted as ND 4.3\%, NN 13\%, AUS 1\%, SUMP $2.8 \%$, SM $4.3 \%$, and M 11.6\%.

On histopathological follow-up (Table 4), one case diagnosed as inadequate on cytology was later reported as chronic sialadenitis on histopathology. The reason for this was the cytological smears were sparse in cellularity and no inflammatory cells were seen in any of the smears. Histopathological follow-up was available in three cases diagnosed as cystic lesion on cytology. Out of this, one case was diagnosed as pleomorphic adenoma. The reason of this case was misdiagnosed appears to be because it presented as a swelling of $3 \mathrm{~cm}$ which appeared to be a cystic swelling. The misdiagnosis in this case can be rendered more to the sampling technique rather than a wrong interpretation of the smears. Thus, we realized that in such cases, FNAC should be done from both the solid and the cystic components. Pantanowitz et al., ${ }^{22}$ had encountered similar problem in their study and have proposed a comprehensive management protocol for the cystic lesions. The other case was diagnosed as mucoepidermoid carcinoma. We encountered similar problem in this case as well. The presence of predominant cystic component in the swelling was considered as the representative of the entire lesion. Hence, the smears were scant in cellularity and had only the cyst fluid. The third case was reported as warthin tumor. Two cases reported as epidermal cyst was later reported as pleomorphic adenoma. Out of this, one case on reclassification by the Milan system was reclassified in the category AUS because of the presence of considerable cellularity and presence of chondromyxoid stroma in the background. Eight cases of chronic sialadenitis were available for histopathological follow-up and were reported as same.

One case which was later diagnosed as warthin tumor was diagnosed as a neoplastic process of salivary gland origin on cytology. This case presented to us with a massive swelling measuring around $15 \mathrm{~cm}$. Most of the component of the swelling was cystic, and on physical examination, the solid component was palpated only partly. The smears on cytological evaluation showed features of warthin tumor and on recategorization by Milan system were recategorized into category of benign salivary gland neoplasm.

Three cases diagnosed as salivary gland neoplasm with no other differential diagnosis provided by cytopathologists 
were later reported otherwise on histopathology. One of this case was reported as papillary cystadenocarcinoma which constituted a false-negative case, the other was reported as adenoid cystic carcinoma, and one case was reported as oncocytoma on histopathology. One case reported as salivary gland neoplasm with atypia on cytology was reported as pleomorphic adenoma on histopathology. It was the only false-negative case reported in our study.

All five cases available for histopathology of cytological malignant diagnoses were true positive cases. This included two cases of mucoepidermoid carcinoma, and one case each of acinic cell carcinoma and adenoid cystic carcinoma. Sixteen cases of pleomorphic adenoma were available for histopathological follow-up and were reported as same.

The correlation in the cytological and histopathological diagnosis was observed and sensitivity and specificity, and diagnostic accuracy was calculated (Table 5). The sensitivity and specificity as reported by our study were $71.4 \%$ and $96.1 \%$. This was in concordance with the comparative studies by Piccoioni et al., ${ }^{23}$ Stow et al., ${ }^{24}$ Lukas and Duskova, ${ }^{25}$ and Jayaram and Dashini. ${ }^{26}$ The diagnostic accuracy as reported by our study is $62.5 \%$. This is lower than that reported by comparative studies. The positive predictive and negative predictive value as reported by our study are $83.3 \%$ and $92.5 \%$, respectively. This was comparable to that reported by Jain et al., ${ }^{27}$ and Mukundapai et al. ${ }^{28}$

\section{Limitations of the study}

A particular limitation of our study was that in a number of cases histopathological diagnosis was not available since few cases did not undergo surgical excision at our institute.

\section{CONCLUSION}

FNAC has, therefore, been an easy, accurate, and feasible investigation in experienced hands in the diagnosis of salivary gland lesions. To conclude, FNAC of salivary glands is a safe, effective, economical outpatient procedure and should be considered as first investigation in the management of salivary gland lesions. The new formulation of Milan system has served to bridge the communication barrier between the pathologists and clinicians. This system has aided in better management of the underlying pathology as it offers a consensual reporting system by the pathologists and its specific clinical course by the clinicians.

\section{ACKNOWLEDGMENT}

The authors take this opportunity to thank the department of pathology and ENT for their wholehearted support for this study.

\section{REFERENCES}

1. Seethala RR, Livolsi VA and Baloch ZW. Relative accuracy of fine needle aspiration and frozen section in the diagnosis of lesions of the parotid gland. Head Neck. 2005;27(3):217-223. https://doi.org/10.1002/hed.20142

2. Koirala S, Sayami G and Pant AD. Correlation of FNAC and histopathology in diagnosis of salivary gland lesions. J Pathol Nepal. 2014;4:654-657.

https://doi.org/10.3126/jpn.v4i8.11593

3. Jan IS, Chung PF, Weng MH, Huang MS, Lee YT, Cheng TY, et al. Analysis of fine-needle aspiration cytology of the salivary gland. J Formos Med Assoc. 2008;107(5):364-370.

https://doi.org/10.1016/s0929-6646(08)60101-1

4. Rossi ED, Baloch Z, Pusztaszeri M and Faquin WC. The Milan system for reporting salivary gland cytopathology (MSRSGC): An ASC-IAC sponsored system for reporting salivary gland fine needle aspiration. J Am Soc Cytopathol. 2018;7(3):111-118. https://doi.org/10.1016/j.jasc.2018.02.002

5. Bancroft JD and Layton C. The hematoxylins and eosin. In: Suvarna SK, Layton C and Brancroft JD, editors. Bancroft's Theory and Practice of Histological Techniques. $7^{\text {th }}$ ed. New York: Churchill Livingstone Elsevier; 2013. p. 178-179.

https://doi.org/10.1016/b978-0-7020-4226-3.00010-x

6. Kumar B, Joshi U, Pant B and Arya D. Diagnostic discrepancies in fine needle aspiration diagnosis of parotid gland lesions in a resource limited hilly region. Indian $\mathrm{J}$ Pathol Microbiol. 2018;5(2):221-229.

https://doi.org/10.18231/2394-6792.2018.0042

7. Goel A and Kaushal M. Diagnostic utility of fine needle aspiration cytology in salivary gland tumors. Saudi J Med. Pharm Sci. 2018;5:638-644.

8. Sharma M, Bala N, Angral S, Kapoor M and Goel M. FNAC of salivary gland lesions with histopathological and clinical correlation. Int J Oral Health Med Res. 2015;2:8-12.

9. Panchal U, Shah I and Goswami H. A cytological and histological comparative study of salivary gland lesions at tertiary heath care centre. Int J Biomed Adv Res. 2015;6(6):470-474.

10. Ameli F, Baharoom A, Md IN and Noor AS. Diagnostic challenges in fine needle aspiration cytology of salivary gland lesions. Malays J Pathol. 2015;37(1):11-28.

11. Rohilla M, Singh P, Rajwanshi A, Gupta N, Srinivasan R, Dey P and Vashishta RK. Three-year cytohistological correlation of salivary gland FNA cytology at a tertiary center with the application of the Milan system for risk stratification. Cancer Cytopathol. 2017;125(10):767-775. https://doi.org/10.1002/cncy.21900

12. Kennedy TL. Warthin's tumor: A review indicating no male predominance. Larygnoscope. 1983;93(7):889-891. https://doi.org/10.1288/00005537-198307000-00008

13. Orell SR and Klijanienko J. In: Orell SR and Sterrett GF, editors. Head and Neck. $5^{\text {th }}$ ed. Edinburg: Churchill Livingstone Elsevier; 2011. p. 38-76.

14. Ersoz C, Uguz AH, Tuncer $U$, Soylu $L$ and Kiroglu M. Fine needle aspiration cytology of the salivary glands: A twelve years' experience. Aegean Pathol J. 2004;1:51-56.

15. Singh A, Haritwal A and Murali B. Correlation between cytology and histopathology of the salivary glam. Aust Med J. 2011;4(2):66-71.

https://doi.org/10.4066/AMJ.2011.518

16. Kumar Y, Permi H, Parameesha, Kishan, Prasad H, Teerthnath $S$, et al. Role of fine needle aspiration cytology in salivary gland 
tumours in correlation with their histopathology: A two year prospective study. J Clin Diagn Res. 2011;7:1375-1380.

17. Devi J. Diagnostic accuracy of fine needle aspiration cytology in salivary gland neoplasms. Int $\mathrm{J}$ Med Sci Clin Invent. 2018;5(2):3532-3536.

18. Amita K, Rakshitha HB, Singh A and Shankar V. Evaluation of accuracy of Milan system for reporting salivary gland cytology: Review of morphology and diagnostic challenges in each category. J Cytol. 2020;37(1):18-25.

https://doi.org/10.4103/JOC.JOC_191_18

19. Kaushik R, Bhatia K, Sarin H, Gautam D and Sarin D. Incorporation of the Milan system in reporting salivary gland fine needle aspiration cytology: An insight into its value addition to the conventional system. Diagn Cytopathol. 2020;48(1):1729. https://doi.org/10.1002/dc.24321

20. Kala C, Kala $S$ and Khan L. Milan system for reporting salivary gland cytopathology: An experience with the implication for risk of malignancy. J Cytol. 2019;36(3):160-164.

https://doi.org/10.4103/JOC.JOC_165_18

21. Katta R and Chaganti P. Application of Milan System of reporting salivary gland cytopathology-A retrospective cytohistological correlational study. J Dr NTR Univ Health Sci. 2019;8(1):11-17. https://doi.org/10.4103/JDRNTRUHS.JDRNTRUHS_52_19

22. Pantanowitz L, Thompson $L$ and Rossi ED. Diagnostic approach to fine needle aspirations of cystic lesions of the salivary gland. Head Neck Pathol. 2018;12(4):548-561.

https://doi.org/10.1007/s12105-018-0904-8

23. Piccoioni LO, Fabiano B, Gemma M, Sarandria D and Bussi M. Fine needle aspiration cytology in diagnosis of parotid lesions. Acta Otorhinolaryngol Ital. 2011;31(1):1-4.

24. Stow N, Veivers D and Poole A. Fine-needle aspiration cytology in the management of salivary gland tumors: an Australian experience. Ear Nose Throat J. 2004;83(2):128-131.

25. Lukas $\mathrm{J}$ and Duskova J. Fine-needle aspiration biopsy in the diagnosis of tumors and non-neoplastic lesions of salivary glands. Bratisl Lek Listy. 2006;107(1-2):12-15.

26. Jayaram $\mathrm{G}$ and Dashini $\mathrm{M}$. Evaluation of fine needle aspiration cytology of salivary glands: An analysis of 141 cases. Malays $\mathrm{J}$ Pathol. 2001;23(3):93-100.

27. Jain R, Gupta R, Kudesia M and Singh S. Fine needle aspiration cytology in diagnosis of salivary gland lesions: A study with histologic comparison. Cyto J. 2013;10:5. https://doi.org/10.4103/1742-6413.109547

28. Mukundapai M, Sharma N, Patil A and Gopal C. Fine-needle aspiration cytology of salivary gland lesions: A revised classification based on Milan system 4 year experience of tertiary care cancer centre of South India. J Cytol. 2020;37(1):12-17. https://doi.org/10.4103/JOC.JOC_68_18

\section{Authors' Contributions:}

SS- Concept and design of the study, reviewed the literature, and prepared first draft of manuscript; PR-Interpreted the results and revision of manuscript; SK-Revision of manuscript; DA, UG, and AS- Revision of the manuscript.

Work attributed to:

BPS GMC for Women, Khanpur Kalan, Haryana, India

Source of Funding: None, Conflicts of Interest: None. 